\title{
Planning sensor locations for the detection of radioactive plumes for Norway and the Balkans*
}

\author{
K.B. Helle ${ }^{1}$, L. Urso ${ }^{2}$, P. Astrup ${ }^{3}$, T. Mikkelsen ${ }^{3}$, J.C. Kaiser ${ }^{2}$, E. Pebesma ${ }^{1}$, \\ C. Rojas-Palma ${ }^{4}$, E. Holo ${ }^{5}$, J.E. Dyve ${ }^{5}$ and W. Raskob ${ }^{6}$ \\ ${ }^{1}$ Institut für Geoinformatik (ifgi), Westfälische Wilhelms-Universität Münster, Germany, \\ e-mail: kristina.helle@uni-muenster.de \\ ${ }^{2}$ Institut für Strahlenschutz (ISS) - Helmholtz-Zentrum München, Germany \\ ${ }^{3}$ Risø Nationallaboratoriet for Bæredygtig Energi, Danmarks Tekniske Universitet, Denmark \\ ${ }^{4}$ Studiecentrum voor Kernenergie (SCK-CEN), Mol, Belgium \\ ${ }^{5}$ Statens Strålevern (NRPA), Østerås, Norway \\ ${ }^{6}$ Karlsruher Institut für Technologie (KIT), Eggenstein-Leopoldshafen, Germany
}

\begin{abstract}
Locations of gamma dose rate sensors have often been chosen by administrative or geometrical criteria. Nowadays computational capacity allows for a more realistic basis. We use simulations of potential radioactive plumes based on weather data of one year to investigate the threats to regions without own nuclear power plants and to find good numbers and locations of sensors to detect such plumes. We optimise sensor locations by minimising a cost function that can take into account numbers of undetected plumes, their dose to the region in general, or on the population. Besides we assess the effect of administrative constraints, be it that sensors have to cover administrative units, or that optimisation is done for sub-regions separately. Finally we evaluate the robustness of the approach if less or other plumes are used. The main findings are that sensors at boundaries are often best, but also typical paths of plumes may be important, and that administrative constraints may necessitate much more sensors. The small numbers of sensors actually deployed in these regions seem sufficient. However, the latter may be an artefact of the low number of plumes we considered. Altogether, combined with other considerations, this approach can contribute to better decisions about gamma dose rate sensor locations.
\end{abstract}

\section{INTRODUCTION}

In this study we investigate where radioactive plumes from abroad are likely to pass and where sensors should be located to detect them. Starting from scratch we add sensors until all considered plumes can be detected or until a desired number of sensors is reached. This is based on simulated plumes from several nuclear power plants in neighbour countries of the region of interest. The weather data for the simulations is derived from reanalysis data for a full year. For more simple simulations, there has been research on multi-objective optimisation of sensor locations [1]. Adapting existing monitoring networks was treated in an earlier publication [2].

In Norway and the Balkans (Albania, Bosnia, Croatia, Macedonia, Montenegro, Serbia (incl. Kosovo)) no commercial nuclear power plants exist but threats from abroad. In both regions rather sparse sensor networks are operated, which are mainly meant for detection of radioactive plumes and to trigger more monitoring in emergencies. The main focus is on Norway, the Balkans serve for comparison and also to test the effect of national versus international optimisation.

\footnotetext{
*The current investigation is part of the research project DETECT "Design of optimised systems for monitoring of radiation and radioactivity in case of a nuclear or radiological emergency in Europe".
} 


\section{METHODS AND DATA}

\subsection{Plume simulations}

The plume simulations for this study are made with the RIMPUFF dispersion model [3, 4]. The input meteorological data with one hour resolution is calculated with the Weather Research and Forecast Model [5], based on NCEP reanalysis data [6, 7]. During all of 2007 a new twelve hour release is started every $84 \mathrm{~h}$ and simulated for up to seven days. The nuclide vector consists of Kr-88, Sr-91, I-131, Xe133, Xe-135, and Cs-137 at a constant release rate of $1 \cdot 10^{12} \mathrm{~Bq} / \mathrm{s}$ for each nuclide, released as puffs every $30 \mathrm{~min}$. Release height is $50 \mathrm{~m}$ (or $1550 \mathrm{~m}$ ) and no heat is considered. The releases are started at locations of nuclear power plants possibly threatening the regions of interest, these are Chernavoda (RO), Kozloduy (BG), Krsko (SI), Paks (HU), and Temelin (CZ) for the Balkans; Forsmark (SE), Kola (RU), Ringhals (SE), Torness (UK), and another source close to Andoya $\left(15.5^{\circ} \mathrm{E}, 69.5^{\circ} \mathrm{N}\right)$, to take into account threats from nuclear powered navy vessels, for Norway. The resulting dose rates are computed at a grid with $4 \mathrm{~km}$ resolution. We optimise sensors for three different sets of simulations, for the Balkans $50 \mathrm{~m}$ release height and for Norway with both heights.

\subsection{Cost functions and optimisation}

The aim of the optimisation is to minimise the cost function that assigns a value to each given set of sensors. The cost function is based on the simulated plumes. For each plume $i \in I$, for all time intervals $t \in T$ and locations (grid cells) $x \in X$, the gamma dose rate $r_{i}(x, t)$ is known from the simulations. We only care, if a plume could be detected at a location at all during the whole plume passage. The detection threshold is set to $100 \mathrm{nSv} / \mathrm{h}$ based on different national limits for early warning in Europe. Therefore the following indicator function (1) is used

$$
K(i, x)=\left\{\begin{array}{l}
1 \text { if } \forall t \in T: \mathrm{r}_{i}(x, t) \leq 100 \mathrm{nSv} / \mathrm{h} \\
0 \text { else (i.e. if plume } i \text { is detected at location } x \text { ) }
\end{array}\right.
$$

For a set of sensors $S=\left\{x_{1}, \ldots, x_{m}\right\} \subseteq X$, the cost (2) is the weighted number of plumes that are not detected by any of the sensors

$$
c(S)=\sum_{i \in I} w(i) \cdot \prod_{x_{j} \in S} K\left(i, x_{j}\right)
$$

We apply three different weights to take into account the different effect of plumes and to focus on the important ones. The simplest weight is $w_{\text {number }}(i) \equiv 1$ for $c_{\text {number }}$, the number of undetected plumes. The importance of the plumes is considered either by the total dose of the plume to the area of interest $w_{\text {area }}(i)=\sum_{x \in X} \sum_{t \in T} \mathrm{r}_{\mathrm{i}}(\mathrm{x}, \mathrm{t})$ for $c_{\text {area }}$ or by the total dose of the plume to the population in this area $w_{\text {population }}(i)=\sum_{x \in X}^{x \in X} p(x) \sum_{t \in T} \mathrm{r}_{\mathrm{i}}(\mathrm{x}, \mathrm{t})$ for $c_{\text {population where }} p(x)$ is the population in the grid cell $x \in X$. The Norwegian population is derived from a map of all settlements with more than 200 inhabitants [9] assuming equal distribution of the remaining $21 \%$ of the population. For Norway high release and the Balkans only $c_{\text {number }}$ is used, for Norway low release we use all cost functions.

The optimisation algorithm is greedy search. All grid cells are considered possible sensor locations. First the sensors are added one-by-one: to find the best next sensor location, we compute for each location the cost if an additional sensor would be placed here. Always the best sensor is added -if there are several, we take the most south-western one- and the whole step is repeated. Then all redundant sensors are deleted, to find the smallest set of sensors that still can detect all considered plumes. If required, we continue deleting sensors, removing always the least important one, until the desired number of sensors is reached. Deleting some of the sensors can also avoid overfitting as it will first remove the sensors that are only needed for exclusive detection of single plumes. For Norway we chose 


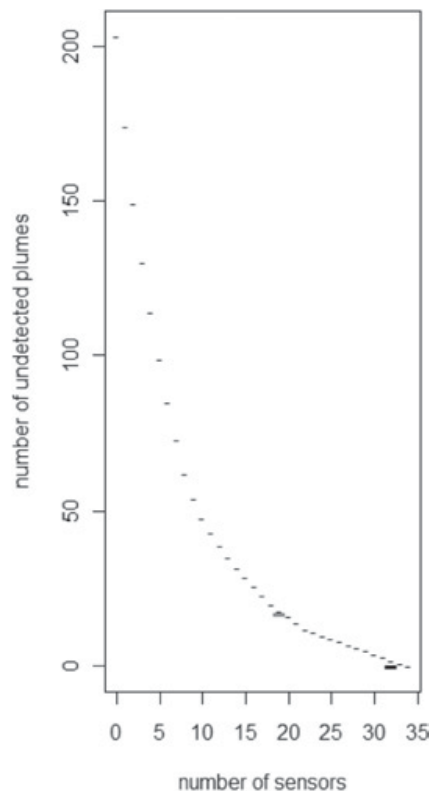

Figure 1. $c_{\text {number }}$ for sensors added one-by-one; bold black -redundant sensors deleted; bold grey -final sensors with desired number.

19 sensors as this fits the number of administrative units, for Balkans 16 sensors correspond to a similar density. Figure 1 shows the values of $c_{\text {number }}$ during optimisation for Norway low release.

Often locations of gamma dose sensors have to fulfil political constraints. A typical request is that each administrative unit has at least one sensor. We optimised sensors for Norway low release under this constraint for the 19 administrative units ("fylke"). When adding sensors, each has to be placed in a different "fylke" until there is one in each. When deleting sensors, it is not allowed to take the last sensor from a "fylke". Another political issue is, if agencies of neighbouring countries trust each other, or if each one wants to run enough sensors itself to be independent. The effect of both strategies was investigated for the Balkans, where optimisation was run for the whole region, and then for six sub-regions separately using only plumes that are detectable in the respective sub-regions.

The optimisation result may be very sensitive towards the set of plumes considered. Therefore we run the whole optimisation for Norway low release on reduced sets of plumes. First we excluded regularly $1 / 20,1 / 10,1 / 4$, or $1 / 2$ of the plumes respectively. Second we excluded all 75 plumes from one source (Andoya) or 75 random plumes. In each case we determined the full set of sensors that can detect all of the remaining plumes and the 19 most important sensors. For these we tested, how well they could detect the plumes not considered in the optimisation and how the locations changed. In addition we compared the optima for high and low release.

For cost functions and optimisation we used the statistical programming language $\mathrm{R}$ [8].

\section{RESULTS}

\subsection{Properties of the plumes}

From the 104 simulated plumes from each source, many never reach the region of interest. Of the 520 plumes from the five sources considered in both use cases respectively, only 295 for the Balkans and 203 or 194 for Norway (low and high release respectively) can be used for the optimisation. Most plumes are small, Table 1 shows statistics on how much of the area is covered by one plume. The plumes for 
Table 1. Fraction of the area of interest covered by the single plumes: Numerator and denominator are numbers of cells, each cell has $16 \mathrm{~km}^{2}$.

\begin{tabular}{l|cccc} 
& min & median & $\max$ & mean \\
\hline Norway low & $1 / 20255$ & $872 / 20255$ & $7203 / 20255$ & 0.062 \\
Norway high & $1 / 20255$ & $1084 / 20255$ & $12470 / 20255$ & 0.083 \\
Balkans & $1 / 16817$ & $1140 / 16817$ & $10040 / 16817$ & 0.116
\end{tabular}
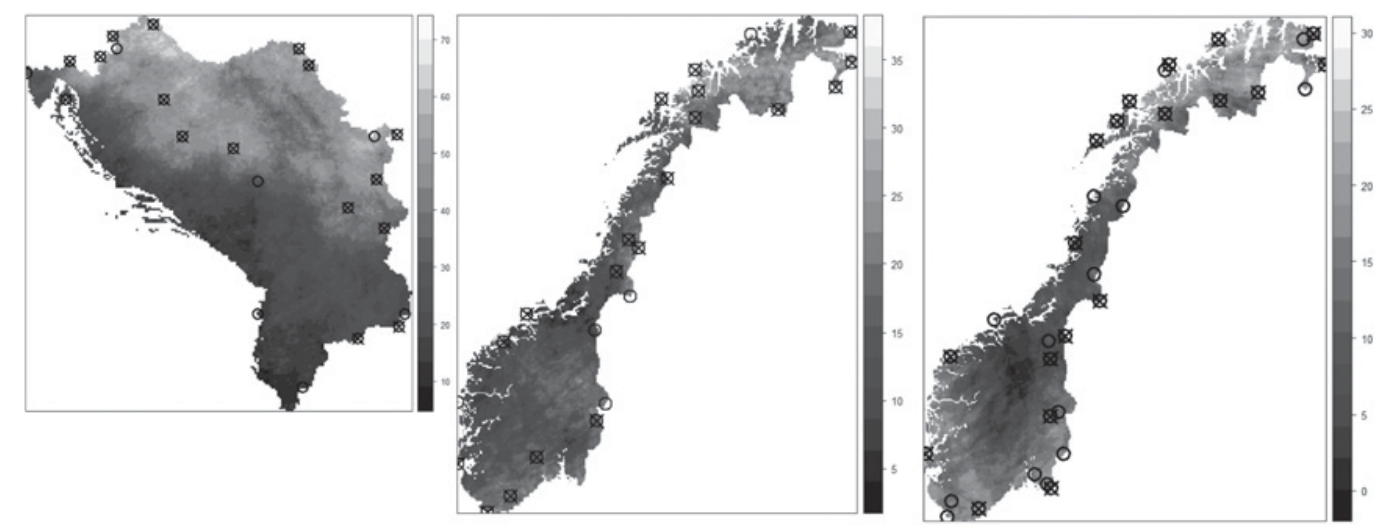

Figure 2. Optimal sensor locations for Balkans, Norway high, Norway low. Full set of sensors: O; 16 or 19 most important sensors: $\otimes$; Background: number of detectable plumes.

Norway are smaller than for the Balkans, especially for low releases, and the area of interest is bigger, therefore on average the fraction covered by each plume is only about half compared to the Balkans (for low release). The low and high release plumes for Norway differ a lot, on average the regions where plumes from the same source and date but of different release heights can be detected, only overlap 1/3. This average contains $27 \%$ cases where there is no overlap at all. In addition there are 113 cases where only one of the two plumes can be detected in Norway.

\subsection{Optimal sensor locations for detection}

The minimal number of sensors to detect all plumes for Norway low release is 32 , whereas for high release 24 sensors are sufficient. For the Balkans 23 are enough, although more plumes are considered there. The best 19 sensors for Norway low release miss 17 of the plumes, for high release they miss six. The best 16 sensors for the Balkans only miss seven. So small plumes as for Norway low release seem to be most difficult to detect. In Norway, sensors should be placed at the coasts and borders. For the Balkans borders are also important, whereas no plumes threaten the region from the coast, but there seems to be a main path of plumes in the centre of the region where sensors should be placed. In all cases, sensors are clustered close to nearby sources like the marine Andoya for Norway and the power plant Krsko for the Balkans, see figure 2.

\subsection{Optimisation for low dose}

The the sensor locations resulting from optimisation with $c_{\text {area }}$ and $c_{\text {population }}$ for Norway low dose differ from those for $c_{\text {number }}$, see figure 3 . Also the number of sensors needed to detect all plumes is higher: 34 and 36 sensors for $c_{\text {population }}$ and $c_{\text {area }}$ respectively. These results are obviously worse than the one from $c_{\text {number }}$ where only 32 sensors are needed for the same detection capability. However, if less sensors are used, those optimised for one cost function always perform best in this respect, see table 2 . 


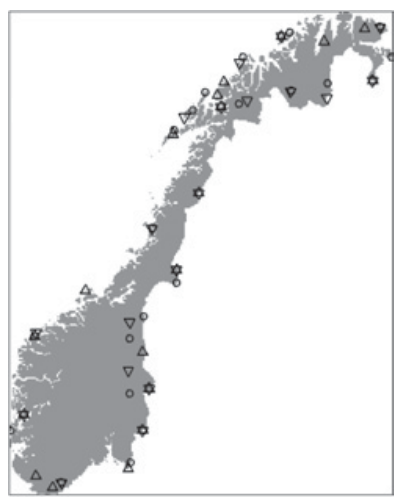

Figure 3. 19 best sensors for $c_{\text {number }}(\mathrm{O}), c_{\text {area }}(\nabla), c_{\text {population }}(\mathrm{O})$.

Table 2. Cost for sets of 19 sensors optimised for different cost functions and for the existing 32 sensors.

\begin{tabular}{l|ccc} 
optimised for & $c_{\text {number }}$ & $c_{\text {area }}$ & $c_{\text {population }}$ \\
\hline$c_{\text {area }}$ & 21 & 0.039 & 16.0 \\
\hline$c_{\text {population }}$ & 22 & 0.083 & 13.9 \\
\hline existing & 49 & 1.241 & 209.0
\end{tabular}

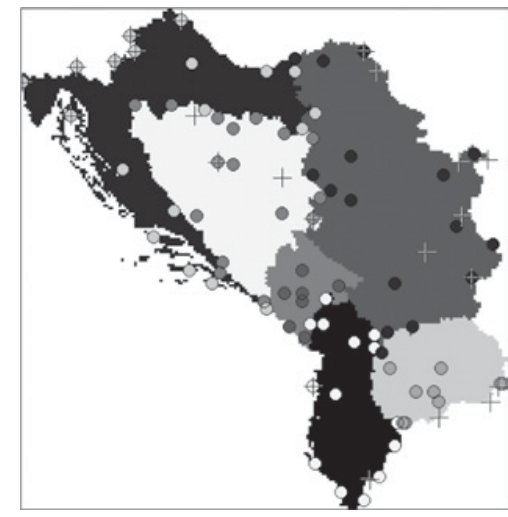

Figure 4. Full sets of sensors O: optimised for subregions separately + : optimised for the whole region.

On the one hand the constraint, that each "fylke" must have at least one sensor, considerably impairs the result for Norway. The first four sensors can be located as before, but for further sensors the constraint only allows suboptimal locations. Altogether 39 sensors are needed to detect all plumes and the 19 best ones leave 56 plumes undetected. Thus about six more sensors than else are needed. On the other hand the sensors optimised without this constraint are very far from meeting it: the 19 best sensors are located in only ten of the "fylke".

Optimising sensor locations for sub-regions of the Balkans clearly showed that much more sensors are needed if each sub-region wants to be independent, see figure 4 . For the latter, 75 sensors are necessary, whereas for joint sampling 23 sensors are sufficient. 13 of the sensors are the same in both cases, mainly in Croatia where most plumes come from the nuclear power plant Krsko very close to the border. 
Table 3. Results from optimisation with less or different plumes.

\begin{tabular}{l|c|c|c|c|c|c|c|c|c} 
mean number of & plumes & all & $\begin{array}{c}\text { regular } \\
95 \%\end{array}$ & $90 \%$ & $75 \%$ & $50 \%$ & random & $\begin{array}{c}\text { without } \\
\text { Andoya } \\
(193)\end{array}$ & $\begin{array}{c}\text { high } \\
\text { release } \\
(183)\end{array}$ \\
& sensors & $(203)$ & $(153)$ & $(102)$ & $(128)$ & $(128)$ & $(194)$ \\
\hline sensors & all & 32 & 30.6 & 29.5 & 27.8 & 22 & 26 & 24 & 24 \\
\hline undetected & all & 0 & 2.1 & 4.1 & 11 & 25 & 14.6 & 26 & 49 \\
plumes & $\mathbf{1 9}$ & 17 & 17.9 & 18.2 & 24 & 30 & 26.8 & 34 & 62 \\
\hline sensors & all & all & 21.4 & 19.6 & 15 & 10 & 12.2 & 12 & 3 \\
coinciding & $\mathbf{1 9}$ & 19 & 9.2 & 9.4 & 7 & 6 & 4.8 & 4 & 1 \\
with original & & & & & & & & &
\end{tabular}

\subsection{Robustness}

As described in table 3, the number of sensors needed to detect all plumes grows with the number of plumes. By chance about $79 \%$ of the plumes not considered in the optimisation are still detected, even those with $89 \%$ of the dose and with $95 \%$ of the dose to humans. This fraction is similar for all regular and random subsets but worse if a complete source is ignored. From a different point of view, the 19 best sensors optimised without plumes from Andoya, miss 6 of these and 28 from Andoya whereas when all plumes are considered, the 19 best sensors miss 1 plume from Andoya and 16 else.

The sensor locations also depend a lot which plumes were omitted. From the full set of sensors between 9 and 27 coincide with the original ones. The differences for 19 best sensors are even bigger. There are also big differences among them, one location occurs in 39 of the 43 full sets, but the median occurrence is two. In general, the differences increase with the number of omitted plumes. Using high release plumes instead of low release resulted in completely different sensor locations that were not well suited to detect the low release plumes (table 3, last column). The other way it worked better, maybe because the high release plumes were less and bigger: the 19 best low release sensors missed only 41 of them. These results show that the sensor locations are very sensitive to the input and probably more simulated plumes are needed to give realistic results.

\section{DISCUSSION}

The most critical issue seems to be the number of plumes used, but running simulations with less temporal distance may lead to high correlations. Therefore finding a good set of plumes remains a challenge. Different release heights should be used if they are considered realistic.

The optimisation algorithm used here is fast, it only tries very few possible sets of sensors. So it might not find the global optimum. For one case we run a more extended search, it found sets of 19 sensors that can detect one more plume. So the algorithm used here did not find the global optimum but was close.

\section{CONCLUSIONS}

We built an algorithm that allows integrating climatic data into the search for locations for gamma dose rate sensors in regions where threats mainly come from abroad. In our use cases, the best locations for sensors were mainly at boundaries and coasts but also in highly affected regions within the countries. This algorithm also allows focussing on plumes severely affecting the area of interest or the population, yielding intuitive results like more sensors in densely populated areas. Including political constraints like national instead of international monitoring can more than triple the number of sensors needed. In general the results showed, that few sensors (about 1 per $15000 \mathrm{~km}^{2}$ ) were sufficient to detect many of the plumes. However, we also observed that probably more plumes should be used as about $21 \%$ of the not considered ones pass undetected. Altogether this algorithm can contribute substantially to improve 
decisions about gamma dose rate sensor locations, but it should be combined with other approaches for example by linear combination with other cost functions.

\section{Acknowledgments}

This work was funded by the European Commission Seventh Framework Program, Contract N. 232662. The views expressed herein are those of the authors and not necessarily those of the European Commission.

\section{References}

[1] Melles S.J., Heuvelink G.B.M., Twenhöfel C.J.W., van Dijk A., Hiemstra P.H., Baume O., Stöhlker U. "Optimizing the spatial pattern of networks for monitoring radioactive releases", Computers \& Geosciences 37 (2011) 280-288.

[2] Helle K.B., Pebesma E. "Conservative updating of sampling designs". Accuracy 2010, Leicester, UK, N.J. Tate, P.F. Fisher. pp. 181-184.

[3] Mikkelsen T., Thykier-Nielsen S., Hoe S., "Medium-range puff growth", Developments in Environmental Science 6 (2007) 243-252.

[4] Mikkelsen T., Larsen S., Thykier-Nielsen S., "Description of the Ris $\emptyset$ puff diffusion model", Nuclear Technology 67 (1984) 56-65.

[5] WRF. http://www.wrf-model.org/index.php [2011.05.01]

[6] Kalnay E., Kanamitsu M., Kistler R., Collins W., Deaven D., Gandin L., Iredell M., Saha S., White G., Woollen J., Zhu Y., Chelliah M., Ebisuzaki W., Higgins W., Janowiak J., Mo K., Ropelewski C., Wang J., Leetmaa A., Reynolds R., Jenne R., Joseph D. “The NCEP/NCAR 40-year reanalysis project”, Bulletin of the American Meteorological Society 77 (3) (1996) 437-471.

[7] NOAA. http://www.esrl.noaa.gov/psd/ [2011.05.01]

[8] R Development Core Team (2011). "R: a language and environment for statistical computing", http://www.R-project.org/ [2011.05.01]

[9] Statistisk Sentralbyrå (2010). "Kart over tettsteder 2009”, http://www.ssb.no/beftett/ [2011.05.01] 